\title{
THE ELIZAVETOVSKOE SETTLEMENT AND THE ELIZAVETOVSKY BURIAL GROUND IN THE WORKS BY V.P. SHILOV ${ }^{1}$
}

\author{
Sergey I. Lukyashko \\ Southern Scientific Center of Russian Academy of Sciences; Don State Technical University, \\ Rostov-on-Don, Russian Federation
}

\begin{abstract}
The paper analyzes the development of ideas about the ethnic characteristics of the Elizavetovskoe settlement and the burial ground in the works by V. P. Shilov. According to V.P. Shilov's ideas dating back to the first years of his work in the settlement and in the burial ground, the population of the archaeological complex correlated with the meots. These ideas coincided with the widespread at that time opinion of leading experts in this area $-\mathrm{B}$. N. Grakov and K. F. Smirnov. The connection of ideas is traced in the description of the funeral rite. At the same time, the researchers pointed out a strong influence of the middle Don traditions on weapons: spears, darts, several types of arrowheads. Valentin Shilov assumed that the iron ore raw materials were supplied to this territory from the Lipetsk deposits. However, after the excavation of Pyatibratny burial ground 8, V. P. Shilov, without changing his prior beliefs, used the term Scythians in descriptions of the scenes in the golden gorytus and in the sheath of the sword. A clear link of gorytus and sword with the Chertomlyk burial complex paved the path for reassessment of views. By the time of I. B. Brashinsky' work on the burial ground, this viewpoint began to prevail among specialists. Without giving importance to the evidence of the Scythian affiliation of the population, I. B. Brashinsky published the article and later a chapter in the monograph, in which he had categorically called the discovered complexes Scythian. Only in 1986, V. P. Kopylov and K. K. Marchenko argued the Scythian ethnic belonging of the population of the Delta of the Don. Besides, a series of articles by the authors who referred the complex to the Sauromatian population, was published. The parties' arguments are not convincing, though, and the ethnic affiliation of the monument remains uncertain, just as one hundred years ago.
\end{abstract}

Key words: Elizavetovsky burial ground, history of studies and interpretation of the material, Meotians, Scythians, Sauromatians, nomads.

Citation. Lukyashko S.I. The Elizavetovskoe Settlement and the Elizavetovsky Burial Ground in the Works by V.P. Shilov. Vestnik Volgogradskogo gosudarstvennogo universiteta. Seriya 4, Istoriya. Regionovedenie. Mezhdunarodnye otnosheniya [Science Journal of Volgograd State University. History. Area Studies. International Relations], 2018, vol. 23, no. 3, pp. 12-18. (in Russian). DOI: https://doi.org/10.15688/jvolsu4.2018.3.1

УДК 903.223(395.1)

ББК 63.4(2)

Дата поступления статьи: 14.03.2018

Дата принятия статьи: 10.04.2018

\section{ЕЛИЗАВЕТОВСКОЕ ГОРОДИЩЕ И МОГИЛЬНИК В РАБОТАХ В.П. ШИЛОВА ${ }^{1}$}

\author{
Сергей Иванович Лукьяшко \\ Южный научный центр РАН; Донской государственный технический университет, \\ г. Ростов-на-Дону, Российская Федерация
}


лагал поступление железорудного сырья из липецких месторождений. Но после раскопок 8-го Пятибратнего кургана, не меняя прежних взглядов, В.П. Шилов употребляет в описаниях сюжетов на золотом горите и ножнах меча термин «скифы». Явная связь горита и меча с Чертомлыцким комплексом создавала почву для переоценки взглядов. Ко времени начала работ на могильнике И.Б. Брашинского эта точка зрения начинает преобладать в среде специалистов. Не придавая особого значения доказательствам скифской принадлежности населения, И.Б. Брашинский публикует статью, а затем и раздел монографии, в которой безапелляционно называет открытые комплексы скифскими. Лишь в 1986 г. В.П. Копылов и К.К. Марченко аргументировали скифскую этническую принадлежность населения дельты Дона. С другой стороны, появляется серия статей авторов, которые связывают комплекс с савроматами. Аргументы сторон неубедительны, что позволяет утверждать, что этническая принадлежность памятника, как и сто лет назад, не определена.

Ключевые слова. Елизаветовский могильник, история изучения и интерпретации материала, меоты, скифы, савроматы, кочевники.

Цитирование. Лукьяшко С. И. Елизаветовское городище и могильник в работах В.П. Шилова // Вестник Волгоградского государственного университета. Серия 4, История. Регионоведение. Международные отношения. - 2018. - Т. 23, № 3. - С. 12-18. - DOI: https://doi.org/10.15688/jvolsu4.2018.3.1

Всем известно, что древние, в особенности греки и римляне, умели воспитывать героев... Это умение заключалось лишь в том, что они умели изображать в своей истории лучших передовых своих деятелей не только в исторической, но и в поэтической правде. Они умели ценить заслуги героев, умели различать золотую правду и истину этих заслуг от житейской лжи и грязи, в которой каждый человек необходимо проживает и всегда больше или меньше ею марается.

А. Нечволодов. Сказания о Русской земле

Елизаветовский комплекс с момента начала его исследования представлял серьезную загадку донской археологии, во многом по сегодняшний день не разрешенную [8, с. 254-258]. При этом ни у кого не вызывает сомнение, то что это опорный - ключевой памятник, в котором скрыты основные проблемы истории не только региона. В XIX в. работы П. Леонтьева и П.И. Хицунова были ориентированы на поиски дополемоновского Танаиса. И отношение к городищу и окружающему его могильнику вытекало из этой установки.

Раскопки А.А. Миллера, давшие большой материал, тем не менее, не позволяли однозначно определить культурную и тем более этническую принадлежность населения [10, c. $86-130 ; 11$, с. $220-247 ; 12$, с. 97-114]. Но идея дополемоновского Танаиса была доминирующей. Правда, М.И. Ростовцев усомнился в справедливости этого вывода. Поскольку эпиграфические материалы только Недвиговского городища доказывают его имя, а название Елизаветовского городища не имеет эпиграфических доказательств. С другой стороны, по мнению Ростовцева, скифский характер погребального обряда курганных захоронений опровергает гипотезу о Елизаветовском городище как о дополемоновском Танаисе $[13$, с. 524]. «Скифский характер» в цитате М.И. Ростовцева в этой конкретной ситуации не имел смысла этнического определения, этот термин в предложении означал туземный или варварский, не греческий характер погребальной обрядности. Ссылаться на это мнение следует с оговорками.

Раскопки городища в 1927-1928 гг. дали возможность Т.Н. Книпович проанализировать керамический материал, который позволил исследователю наметить генетические связи культуры с кобяковской культурой эпохи поздней бронзы. Второй вывод, вытекавший из полевых исследований, был связан с заключением о том, что город Танаис был основан боспорянами на месте Елизаветовского городища в V-III до н.э., а в первом веке был перенесен на правый берег Мертвого Донца [6, с. 90-110; 7, с. 111-201].

В работах А.А. Миллера и Т.Н. Книпович население характеризуется как местное кочевое. При этом кочевое хозяйствование, стационарное поселение и могильник удивительным образом согласуются в сознании исследователей при помощи гипотезы о постепенном перерастании кочевнического зимника в поселок. Но в этом случае население уже не может называться кочевым.

Судя по докладу на конференции ИИМК АН СССР 1952 г., Б.Н. Граков и А.И. Мелю- 
кова считали, что «Собственно скифам соответствует степная скифская культура; впрочем, нижнедонской ее вариант принадлежит, вероятно, меотам» [2, с. 39-93].

К.Ф. Смирнов включал это население в савроматскую группу. «Они (савроматы. С. Л.) не однородны по своему происхождению и уже в их наиболее ранние племенные объединения, вероятно, входили на западе меоты дельты Дона и Приазовья...» [14, с. 5].

Такими основными положениями характеризовалось знание о памятнике к моменту начала работ В.П. Шилова. Валентин Павлович к началу работ на городище был уже достаточно опытным специалистом. В 1941 г. он закончил кафедру археологии Ленинградского университета. Участник и инвалид Великой Отечественной войны. В 1951 г. защитил кандидатскую диссертацию на тему «Население Прикубанья конца VII - середины IV в. до н. э.» [15]. В статье 1950 г. он предпринял первую попытку локализации отдельных меотских племен. На начало 50-х гг. XX в. такого уровня специалистов по меотской культуре в стране больше не было.

В Ростове-на-Дону в это время своих археологов не было. Первый остепененный местный археолог Георгий Александрович Иноземцев, демобилизованный из армии в звании полковника Герой Советского Союза, работал директором библиотеки Карла Маркса. Занимался краеведением, и только в 1956 г. защитил кандидатскую диссертацию по эпохе бронзы на Дону и был приглашен на должность декана исторического факультета РГУ. В пединституте на истфаке преподавал археологию 3.А. Витков, он занимался казачьими городками. В областном музее в это время активно работал большой любитель краеведения директор музея Семен Маркович Марков. Активно занимаясь охраной памятников, Семен Маркович вышел на заключение договора на раскопки Елизаветовского могильника, через территорию которого должен был пройти газопровод. Для выполнения этой работы в Ростове он не видел специалистов. Но в ходе работ Волго-Донской экспедиции Ростовский областной музей краеведения (РОМК) был базой для приезжавших в экспедицию столичных археологов. Имеются свидетельства того, что Семен Маркович был в особенно близких отношениях с А.А. Иессеным и, по-видимому, именно А.А. Иессен рекомендовал С.М. Маркову В.П. Шилова как близкого к теме специалиста. Руководителем Волго-Донской экспедиции был М.И. Артамонов, и поэтому костяк экспедиции был представлен ленинградцами. Это обстоятельство повлияло на формирование ростовской археологической школы, она формировалась на базе ленинградских экспедиций и прежде всего кобяковской экспедиции, руководителем которой была С.И. Капошина. Заботливо опекая местных студентов, Серафима Ивановна многим из них дала путевку в жизнь: это С.Н. Братченко, В.Я. Кияшко, В.С. Бочкарев, В.Е. Максименко, В.М. Косяненко (в то время В.М. Жибура) и мн. др.

Валентин Павлович в 1952 г. проводил раскопки городища Елизаветинское I на Кубани, где ему посчастливилось исследовать керамические печи, а главное, соприкоснуться в поле с материалом, который был предметом его научных интересов. Но отношения с краснодарским археологом Н.В. Анфимовым у него не сложились. Впрочем, они не складывались и у других столичных исследователей. Хорошо известно трепетное отношение Н.В. Анфимова к памятникам Кубани и нежелание кого бы то ни было к ним допускать. В 1953 г. завершались работы Сталинградской экспедиции, в составе которой работал В. П. Шилов, и поэтому предложение Семена Марковича оказалось как нельзя кстати.

Таким образом, на Дону появился археолог, который знал археологию Волго-Донской степи и Кубани. Так уж устроено человеческое сознание, что оно соотносит новое с предыдущим опытом. В.П. Шилов в этом отношении был самой удачной фигурой. Была создана совместная с РОМК Южно-донская археологическая экспедиция, которую с 1954 г. возглавлял В.П. Шилов.

В 1954 г. было раскопано 14 курганов. Отчет Валентина Павловича написан очень хорошо. В первой части отчета дана история изучения Елизаветовского комплекса. Описание раскопов соответствовали уровню описаний середины прошлого века. Я не могу разделить замечание И.С. Каменецкого о том, что копал он не всегда хорошо. «Так, копая один из Пятибратних курганов, подаривших 
ему богатейшее погребение, он выбрал механизмами только середину, оставив края, где находилась крепида, которая раскрылась только в месте въезда скрепера» [4, с. 142]. Отмечу, что в отчете 1954 г. Валентин Павлович пишет: «Как сообщал П.И. Хицунов, все пять курганов были окружены “толстыми стенами из булыжника", то есть крепидами, от которых в настоящее время не сохранилось никаких следов. Камень был выбран жителями окрестных хуторов на различные хозяйственные постройки» [16, с. 15]. Вероятно, делая это замечание, И.С. Каменецкий не удостоил чести отчет Валентина Павловича. Напротив, отмечу, что работе Валентина Павловича в поле предшествовала тщательная работа в архиве, чего мы сегодня не наблюдаем у большинства исследователей. Нередки случаи, когда ранее открытые памятники открываются заново, получают новое имя и под этим именем начинают фигурировать в литературе. Валентин Павлович изучил тексты отчетов П.И. Хицунова и на протяжении ряда лет сопоставлял материалы на местности, до тех пор, пока не убедился в соответствии 8-го кургана кургану, который начинал копать П.И. Хицунов и где он по отчету наткнулся на ограбленное погребение. В.П. Шилов вычислил, что это было не погребение человека, а погребение коня во входе в склеп. Поэтому я опротестовываю обвинение Валентина Павловича в недобросовестности. Тем более смешным выглядит обвинение в стремлении копать большие курганы из-за желания найти ценные находки. Это обвинение можно предъявить большинству коллег. Как часто в мемуарной литературе тому или иному исследователю навешиваются нелестные ярлыки, часто отражающие какую-то одну грань его биографии или лишь одни часто личные отношения приязни или неприязни. На человека ставится клеймо, и позитивная работа уходит на второй план. Так случилось и с С.И. Капошиной и В.П. Шиловым. Донская же археология всегда будет благодарна этим исследователям, многое сделавшим для развития региональной науки. Так, Валентин Павлович, давно утратив интерес к Дону, регулярно просматривал Азовские сборники и обращался к директору музея с письмами, в которых давал дельные замечания по совершенствова- нию издательской деятельности. Кстати, и библиотека В.П. Шилова отложилась в Азовском музее.

В ходе предпринятых в 1954 г работ в кургане 3 группы Пятибратних курганов была обнаружена могильная яма, стены которой были обложены дикарным камнем. Толщина стен 0,5 м, высота от дна 0,6 м. Поверх стен прослежены остатки деревянного наката. Тогда, в 1954 г., когда открытие каменного склепа в 8-м кургане было еще впереди, Валентин Павлович напишет в отчете: «Аналогичное каменное сооружение было открыто П.И. Хицуновым в одном из больших курганов в группе "Пять братьев". Таким образом, мы имеем в обеих (так в отчете. - С. Л.) случаях по существу каменный склеп, перекрытый сверху деревянным накатом, то есть погребальное сооружение, характерное и для меотских захоронений, в частности для Елизаветинских курганов, исследованных Н.И. Веселовским» [16, с. 32]. Это было первое сопоставление двух одноименных памятников соседних регионов. «В двух захоронениях на деревянных перекрытиях обнаружены кости рыбы (к. 5 и к. 7 гр. “Пять братьев”). Любопытно, что обычай приношения рыбы на могилу покойника опять-таки характерен для меотских племен. Так, Николай Дамасский сообщает, что синды бросают на могилы столько рыб, сколько врагов убил погребенный (Николай Дамасский. Свод странных обычаев. § 41)» $[16$, c. 32].

Отмечая погребение коня в отдельной яме под насыпью кургана, Валентин Павлович замечает: «Обычай захоронения коня в одном кургане с умершим широко известен как на территории Прикубанья, так и Северного Причерноморья» [16, с. 33].

Среди обломков амфор найдено значительное количество костей домашних животных: лошади, барана, а также кости рыб (сом). «Таким образом, мы имеем здесь остатки тризны, так характерных для курганных захоронений Боспора и Прикубанья». В тексте идет сноска на работу Е.Г. Кастанаян [5, с. 124 и сл.].

Исключительный интерес представляют замечания Валентина Павловича о формах железных копий и дротиков и связях этих находок с находками со Среднего Дона. Позже 
это наблюдение повторит А.И. Мелюкова [9]. Любопытно замечание о том, что поступление железа происходило из Липецких месторождений. Но вывод о транспортировке руды по воде и местной выплавке железа, подкрепленный находками криц, выглядит как поспешное заявление. Скорее, следует предполагать транспортировку криц. Да и плавка руды требовала большого количества древесного угля, которого на поселении не было, но для кузнечного производства топлива хватало.

Общий вывод в итоговой части отчета следующий:

«Таким образом, анализ обряда и инвентаря позволяет отнести время погребений с $\mathrm{V}$ до начала III века до н.э. Вместе с тем ряд черт погребального обряда и инвентаря, с одной стороны, сближают их с меотскими захоронениями Прикубанья (Елисаветинские (так в тексте отчета. - С. Л.) курганы), а с другой - с древними погребениями Среднего Подонья - вооружение» [16, с. 45].

1. По итогам работ утверждается отсутствие поселения эпохи бронзы под всей территорией городища скифского времени.

2. Выявлена огромная роль рыболовства: слои чешуи на городище в отдельных местах достигали 10-15 cм. Можно предполагать, что рыболовство так же, как и у меотов Приазовья, явилось одной из ведущих отраслей хозяйственной деятельности населения.

«На основании обряда захоронения трудно предполагать этническое различие населения (речь идет о противопоставлении Пятибратних курганов восточной части могильника небольшим курганам центральной и западной части могильника. - C. Л.).

Основной костяк же населения представлен местным населением, ближе всего стоящим к меотским племенам» [16, с. 75].

Позже Э.С. Шарафутдинова подтвердит выводы об отсутствии кобяковского слоя на городище. Основными выводами ее было заключение о том, что среди находок экспедиции фрагментов кобяковской керамики было ничтожно мало, между исчезновением кобяковского и появлением елизаветовского населения существует лакуна в 200 лет, что как раз и опровергает генетическую связь этих групп.

Кобяковского поселения на месте Елизаветовского не было, это доказал еще В.П. Ши- лов, а присутствие единичных находок кобяковской керамики объясняется Э.С. Шарафутдиновой тем, что кобяковцы могли эпизодически посещать эту территорию.

Соглашаясь с этими выводами, мы не можем не обращать внимания на то, что кобяковцы прибыли на Дон из районов Среднего Закубанья, на это обстоятельство позже обратит внимание И.С. Каменецкий, и это наблюдение имело сильное влияние на его выводы относительно происхождения Елизаветовского населения. Но это все в будущем.

Ситуация серьезно меняется в связи с исследованием 8-го Пятибратнего кургана с каменным склепом и богатым, поистине царским погребением, сопровождавшимся горитом и ножнами меча Чертомлыкского типа. Впрочем, Валентин Павлович не отказывается от интерпретации памятника и оставившего его населения как меотского. Но в описаниях сцен, изображенных на горите и ножнах меча, варвары называются скифами, что создает иллюзию изменения мнения исследователя.

В 60-е гг. руководство экспедицией переходит к И.Б. Брашинскому, к работе на Дону его привлекла С.И. Капошина (устное сообщение И.Б. Брашинского). На Елизаветовском комплексе исследуется курган 31, а А.И. Демченко раскапывает курган 5 на западной окраине г. Ростова-на-Дону. Публикация этих комплексов была сделана И.Б. Брашинским, работа так и называлась: «Раскопки скифских курганов на Нижнем Дону» [1, с. 54-61]. Скифская принадлежность представляемых комплексов для автора была явной, и поэтому он ее не обосновывает. Видимая разница в погребальной обрядности снимается с поразительной легкостью. Близость подпочвенных вод не позволяла рыть глубокие колодцы и строить катакомбы, поэтому в Елизаветовском могильнике преобладают ямы. Позже в научно-популярном издании «Сокровища скифских курганов» он назовет раздел, посвященный 8-му Пятибратнему кургану, «Скифские царские курганы на Дону». И.Б. Брашинский - антиковедэпиграфист, не придававший большого значения этническим характеристикам, и его можно понять.

Следует заметить, что еще один исследователь, работавший на Дону и много времени уделявший изучению меотской культу- 
ры - И.С. Каменецкий, в кандидатской диссертации, защищенной в 1965 г., не сомневался в меотской принадлежности населения дельты Дона [3].

Более поздние наблюдения на эту тему соотносили население с савроматами (Максименко, Берлизов). Лишь В.П. Копылов и К.К. Марченко впервые обосновали принадлежность населения к скифам на основании ряда бытовых традиций и использования населением акинаков, что сегодня выглядит недостаточно убедительно. Акинаков сегодня обнаружено больше в меотских грунтовых могильниках Правобережья Кубани. Но что-то никому в голову не приходит отнести эти могильники к скифам. Ни оружие, ни предметы торевтики не могут определять этническую принадлежность населения.

Мне представляются гораздо более показательными связи керамического комплекса поселения и могильника с меотскими керамическими сериями. Это, прежде всего, относится к так называемым воронковидным мискам [8, с. 254-258].

Таким образом, этническая характеристика населения городища и могильника не может быть признана однозначно решенной и нуждается в дальнейшей разработке.

\section{ПРИМЕЧАНИЕ}

1 Работа выполнена при поддержке программы фундаментальных научных исследований государственных академий наук на 2013-2020 гг. базовой темы НИР «Изучение межкультурных взаимодействий населения Нижнего Дона с древнейших времен до нового времени», № госрегистрации 01201354248.

\section{СПИСОК ЛИТЕРАТУРЫ}

1. Брашинский, И. Б. Раскопки скифских курганов на Нижнем Дону / И. Б. Брашинский // КСИА АН СССР. - М. : Наука, 1973. - Вып. 133. - С. 54-61.

2. Граков, Б. Н. Об этнических и культурных различиях в степных и лесостепных областях европейской части СССР в скифское время / Б. Н. Граков, А. И. Мелюкова // Вопросы скифо-сарматской археологии. - М. : Наука, 1952. - С. 39-93.

3. Каменецкий, И. С. Население Нижнего Дона в I-III вв. н.э. : автореф. дис. ... канд. ист. наук / Каменецкий Игорь Сергеевич. - М., 1965. - 12 с.
4. Каменецкий, И. С. История изучения меотов / И. С. Каменецкий. - М. : Таус. 2011. - 383 с.

5. Кастанаян, Е. Г. Обряд тризны в боспорских курганах / Е. Г. Кастанаян // СА. - М. ; Л., 1950. № 14. - С. 124-138.

6. Книпович, Т. Н. К вопросу о торговых сношениях греков с областью р. Танаиса в VII-V веках до н. э. / Т. Н. Книпович // ИГАИМК. - М. ; Л. : [б. и.], 1934. - Вып. 104. - С. 90-110.

7. Книпович, Т. Н. Опыт характеристики городища у станицы Елисаветовской по находкам экспедиции Гос. Академии истории материальной культуры 1928 г. / Т. Н. Книпович // ИГАИМК. - М. ; Л. : [б. и.], 1934. - Вып. 104. - С. 111-201.

8. Лукьяшко, С. И. К этнической характеристике Елисаветовского городища / С. И. Лукьяшко // Шестая Международная кубанская археологическая конференция : материалы конференции. - Краснодар : Экоинвест, 2013. - 498 с.

9. Мелюкова, А. И. Вооружение скифов / А. И. Мелюкова. - М. : Наука. 1964. - 113 с.

10. Миллер, А. А. Раскопки в районе древнего Танаиса / А. А. Миллер // ИАК. - СПб. : Типография главного управления уделов, 1910. - Вып. 35. C. $86-130$.

11. Миллер, А. А. Раскопки у станицы Елизаветинской в 1911 году / А. А. Миллер // ИАК. - СПб. : Типография главного управления уделов, 1914. Вып. 56. - С. 220-247.

12. Миллер, А. А. Новый источник к изучению связи Скифии с Кавказом / А. А. Миллер // ИРАИМК. - Л. : [б. и.], 1925. - Т. IV. - С. 97-114.

13. Ростовцев, М. И. Скифия и Боспор / М. И. Ростовцев. - Ленинград : Типография I Лениградской Трудовой Артели Печатников, 1925. -622 c.

14. Смирнов, К. Ф. Савроматы Поволжья и Южного Приуралья / К. Ф. Смирнов, В. Г. Петренко // САИ. - М. : Наука, 1963. - Вып. Д 1-9. - 39 с.

15. Шилов, В. П. Население Прикубанья конца VII - середины IV вв. до н.э. : (по материалам городищ и грунтовых могильников) : автореф. дис. ... канд. ист. наук / Шилов Валентин Павлович. - М. ; Л., 1951.-12 с.

16. Шилов, В. П. Отчет о работе Южно-донской экспедиции в 1954 г.у / В. П. Шилов // Архив РОМК. - Ф. 2. - Оп. 6. - Д. 19-СВ.

\section{REFERENCES}

1. Brashinskiy I.B. Raskopki skifskikh kurganov na Nizhnem Donu [Excavations of Scythian Burial Mounds on the Lower Don]. KSIA AN SSSR. Moscow, Nauka Publ., 1973, iss. 133, pp. 54-61.

2. Grakov B.N., Melyukova A.I. Ob etnicheskikh i kulturnykh razlichiyakh v stepnykh i lesostepnykh 
oblastyakh evropeyskoy chasti SSSR v skifskoe vremya [On the Ethnic and Cultural Differences in the Steppe and Forest-Steppe Regions of the European Part of the USSR in the Scythian Time]. Voprosy skifosarmatskoy arkheologii [Questions of ScythianSarmatian Archaeology]. Moscow, Nauka Publ., 1952, pp. 39-93.

3. Kamenetskiy I.S. Naselenie Nizhnego Dona v I-III vv. n.e.: avtoref. dis. ... kand. ist. nauk [The Population of the Lower Don in the $1^{\text {st }}-3^{\text {rd }}$ Centuries BC. Cand. hist. sci. abs. diss.]. Moscow, 1965. 12 p.

4. Kamenetskiy I.S. Istoriya izucheniya meotov [The History of the Study of Meotians]. Moscow, Taus Publ., 2011.383 p.

5. Kastanayan E.G. Obryad trizny v bosporskikh kurganakh [The Rite of Feasts in the Bosporan Barrows]. Sovetskaya arkheologiya [Soviet Archaeology]. Moscow; Leningrad, 1950, no. 14, pp. 124-138.

6. Knipovich T.N. K voprosu o torgovykh snosheniyakh grekov s oblastyu r. Tanaisa v VII$\mathrm{V}$ vekakh do n. e. [On the Greek Trade Relations with the Population of the Area of the Tanais River in the $7^{\text {th }}-5^{\text {th }}$ Centuries BC]. Izvestiya Gosudarstvennoy akademii istorii materialnoy kultury. Moscow; Leningrad, 1934, no. 104, pp. 90-110.

7. Knipovich T.N. Opyt kharakteristiki gorodishcha u stanitsy Elisavetovskoy po nakhodkam ekspeditsii Gos. Akademii istorii materialnoy kultury 1928 g. [The Experience ofCharacterizing the Settlement at the Elizavetovskoe Village Using the Finds of the Expedition of the State Academy of History of Material Culture, 1928]. Izvestiya Gosudarstvennoy akademii istorii materialnoy kultury. Moscow; Leningrad, 1934, no. 104, pp. 111-201.

8. Lukyashko S.I. K etnicheskoy kharakteristike Elisavetovskogo gorodishcha [On the Ethnic Characteristics of the Elizavetovskoe Settlement]. Shestaya Mezhdunarodnaya kubanskaya arkheologicheskaya konferentsiya: Materialy konferentsii [Proceedings of the $6^{\text {th }}$ International Kuban Archaeological Conference]. Krasnodar, Ekoinvest, 2013.498 p.

9. Melyukova A.I. Vooruzhenie skifov [The Scythians' Armament]. Moscow, Nauka Publ., 1964. $113 \mathrm{p}$.

10. Miller A.A. Raskopki v rayone drevnego Tanaisa [Excavations in the Area of Ancient Tanais]. Imperatorskaya arkheologicheskaya komissiya, 1910 , iss. 35, pp. 86-130.

11. Miller A.A. Raskopki u stanitsy Elizavetinskoy v 1911 godu [Excavations at the Elizavetovskoe Settlement in 1911]. Imperatorskaya arkheologicheskaya komissiya, 1914, iss. 56, pp. 220-247.

12. Miller A.A. Novyy istochnik k izucheniyu svyazi Skifii s Kavkazom [A New Source for the Study of Scythia-Caucasus Relations]. Izvestiya Gosudarstvennoy akademii istorii materialnoy kultury. Leningrad, 1925, vol. 4, pp. 97-114.

13. Rostovtsev M.I. Skifiya i Bospor [Scythia and the Bosporus]. Leningrad, Tipografiya Lenigradskoy Trudovoy Arteli Pechatnikov, 1925.622 p.

14. Smirnov K.F., Petrenko V.G. Savromaty Povolzhya i Yuzhnogo Priuralya [Sauromats of the Volga Region and Southern Urals]. SAI. Moscow, Nauka Publ., 1963, iss. D 1-9. 39 p.

15. Shilov V.P. Naselenie Prikubanya kontsa VII - serediny IVvv. do n.e. (po materialam gorodishch i gruntovykh mogilnikov): avtoref. dis... kand. ist. nauk [The Population of the Kuban Area at the End of the $7^{\text {th }}-$ Middle of the $4^{\text {th }} \mathrm{cc}$. BC (Based on the Materials of Settlements and Burial Grounds). Cand. hist. sci. abs. diss.]. Moscow; Leningrad, 1951. 12 p.

16. Shilov V.P. Otchet o rabote Yuzhno-donskoy ekspeditsii v 1954 godu [Report on the Work of the South Don Expedition in 1954]. Arkhiv ROMK, F. 2, Op. 6, D.19-SV.

\section{Information about the Author}

Sergey I. Lukyashko, Doctor of Sciences (History), Professor, Department of Archaeology and History of Culture, Don State Technical University, Gagarina Sq., 1, 344000 Rostov-on-Don, Russian Federation; Head of Laboratory of Archaeology, Southern Scientific Centre of Russian Academy of Sciences, Prosp. Chekhova, 41, 344006 Rostov-on-Don, Russian Federation, sciphica@ssc-ras.ru, http:/ /orcid.org/0000-0001-8085-4652

\section{Информация об авторе}

Сергей Иванович Лукьяшко, доктор исторических наук, профессор кафедры археологии и истории культуры, Донской государственный технический университет, площадь Гагарина, 1 , 344000 г. Ростов-на-Дону, Российская Федерация; заведующий лабораторией археологии, Южный научный центр РАН, просп. Чехова, 41, 344006 г. Ростов-на-Дону, Российская Федерация, sciphica@ssc-ras.ru,https://orcid.org/0000-0001-8085-4652 